\title{
Space Educational Program of the Tokyo University of Science: A Trial for Space Education
}

\author{
By Hideki Sato, Shinichi KImura, Ichiro Ueno, Hideyuki SuzuKI, Tomoaki Tatsukawa, Kozo FuJII, \\ Makoto YAMAMOTO, and Chiaki MUKAI \\ Tokyo University of Science, Tokyo, Japan
}

(Received June 22nd, 2017)

\begin{abstract}
In 2015, Tokyo University of Science (TUS) started the TUS Space Educational Program (T-SEP). This program includes not only lectures on space science and technology but also hands-on trainings with onboard equipment and projectbased learning utilizing parabolic microgravity flight and CANSAT. During such project-based learning process, students learn the complete process involved in space missions, such as mission design, implementation, project management, and operations regarding various constraints. Such learning is very effective for acquiring individual knowledge of space science and technology and also acquiring skills required for space missions. The first author of this paper was one of the first T-SEP students in 2015 and one of the best examples of the impact of this program. In addition, he continues to participate as a mentor to support T-SEP. This paper outlines T-SEP results since 2015 from the viewpoint of a mentor having experience as one of the first students.
\end{abstract}

Key Words: Space Education, Hands-on, Parabolic Flight, CANSAT, Mentor

\section{Introduction}

Tokyo University of Science (TUS) is active in many research areas of space science and technology, such as theoretical research on astrophysics and engineering of space systems. TUS also contributes to the enhancement of science education at the high school and junior high school levels because it produces many science teachers every year. TUS can contribute to the enhancement of space education by combining cutting-edge research activities with educator training. Therefore, the TUS Space Educational Program (TSEP) was started; this program is funded by the Aerospace Science and Technology Promotion Program of the Ministry of Education, Culture, Sports, Science and Technology (MEXT). The purpose of T-SEP is to produce highly specialized educators and engineers by teaching various topics of cutting-edge space research and providing special group experience lessons, such as parabolic flight and CANSAT.

T-SEP started as a half-year pilot program in 2015 to evaluate the curriculum and hands-on materials. Twenty TUS students were selected from the applicant group to participate in 10 lectures, three hands-on programs, and group experience lessons with parabolic flight experiments.

Based on the results of the pilot program, T-SEP started a 1-year full program in April 2016. The program was widely advertised, and applications were accepted not only from TUS but also from other universities and high schools. The number of participants was expanded to 30 , including 12 high school students. In addition to improved learning material, 26 lectures and six hands-on programs were added to the full program. For the group experience lessons, a CANSAT design and development trial was included with the parabolic flight experiment to teach the basic processes related to space systems. Several members of the pilot program were featured as mentors to support the special group experiments. Such trials should be effective at mentoring students to improve their skills both with technology and for education and team management.

T-SEP appears to be quite effective at enhancing knowledge, skill, and motivation for space activities based on the questionnaire results and voluntary post-program activities, such as participation in international conferences and CANSAT competitions. In fact, the first author of this paper was one of the first T-SEP students and one of the best examples of the impact of this program. A group photo of the first students is shown in Fig. 1. This paper outlines T-SEP and its results from 2015 to 2016 .

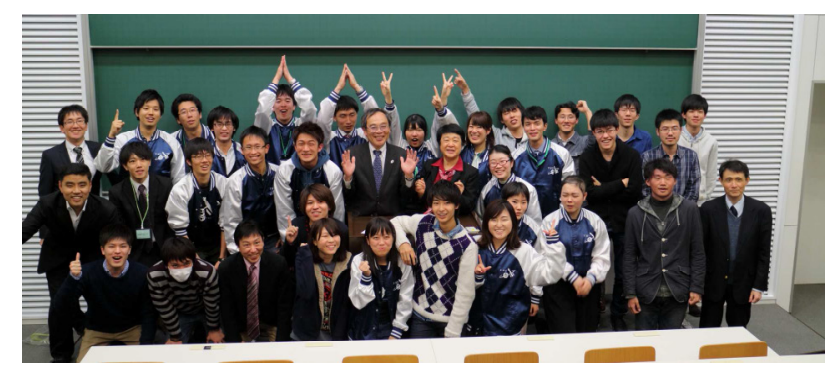

Fig. 1. Group photo of the first students.

\section{Structure of T-SEP}

The T-SEP curriculum consists of four phases: lectures, hands-on trainings, special group experiments, and the communication process. Each phase includes realistic materials, and the participants take part in these four phases 
recursively to further improve their skills and knowledge. The concept of T-SEP is shown in Fig. 2.

First, participants acquire basic knowledge on space science and technologies through lectures not only from researchers but also from guests invited from other universities, the space agency, and the space industry. Table 1 presents T-SEP members. Because these lectures cover a wide range of space science and technology research, such as theoretical research, space engineering, microgravity, and a manned space environment, participants can acquire knowledge of various fields. In addition, the lectures delivered by the invited guests allow participants not only to gain knowledge of cutting-edge space development but also to establish personal relationships with various researchers. Because these lectures are designed to include real-life experiences of the lecturers, participants can receive real knowledge and experience that cannot otherwise be acquired from books or documents.

For the participants, hands-on trials, such as creating something on their own or designing and evaluating their own ideas, are quite effective at promoting a deeper understanding of technology and acquiring practical experience. Some lectures are combined with hands-on trainings, such as assembling space cameras, designing the nozzle of a rocket engine with computer simulations, and operating a satellite. Through such active trials, participants can more actively remember and apply the knowledge acquired from the lectures. Such hands-on trials are designed to utilize realistic materials as much as possible. For example, the data analysis process is taught with real experimental data, and equipment development is taught with real devices and tools.

Special group experiments such as those for parabolic flight or CANSAT are one of the most important phases of TSEP. Participants are divided into groups of four or six members, and each group is expected to design and perform experiments. They are required to decide the objective of the experiment, design the mission configuration and sequence, and develop equipment considering various constraints, such as the size, weight, schedule, cost, and manpower resources. Such a process includes the fundamentals of space missions, such as project management, system design, equipment development, and team management.

Communication is another important part of space missions. It includes presentation skills and communication in foreign languages. When participants perform experiments and obtain results, it is important to share their findings. For the next step, participants are expected to present their findings and exchange their experiences with one another in T-SEP meetings. A few groups with outstanding presentations are encouraged to submit their work to international conferences as part of T-SEP and experience the exchange and communication of information with international researchers. T-SEP includes a foreign shortterm visitation program for participants to learn about international space activities and to improve foreign language communication and emphasize the importance of international cooperation.

T-SEP participants go through these four steps recursively and improve upon their performance in various areas to develop into highly specialized space engineers or educators.

In order to continue enhancing their skills after finishing the program, some members can continue to participate as mentors to support T-SEP. The mentoring system both aims to facilitate the smooth progress of the program and helps the mentor learn about "space education" by gaining experience while teaching students. This will lead to the development of useful human resources with the continuation of the program over time.

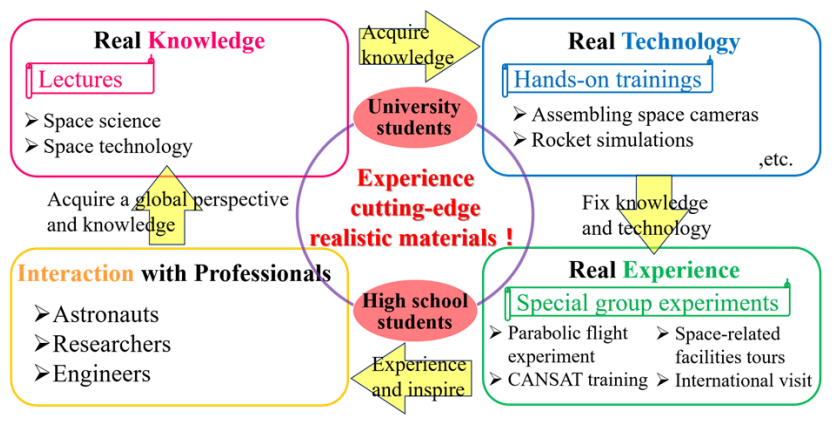

Fig. 2. Concept of T-SEP.

Table 1. T-SEP members.

\begin{tabular}{|c|c|}
\hline Affiliation & Teacher's name \\
\hline Vice-President (Astronaut) & Chiaki Mukai \\
\hline Vice-President & Yasutaka Moriguchi \\
\hline Vice-President & Makoto Yamamoto \\
\hline $\begin{array}{l}\text { Department of Physics, } \\
\text { Faculty of Science Division I }\end{array}$ & Kyoko Matsushita \\
\hline $\begin{array}{l}\text { Department of Chemistry, } \\
\text { Faculty of Science Division I }\end{array}$ & Kazuo Watanabe \\
\hline $\begin{array}{l}\text { Department of Physics, } \\
\text { Faculty of Science Division II }\end{array}$ & Shinji Tsujikawa \\
\hline $\begin{array}{l}\text { Department of Architecture, } \\
\text { Faculty of Engineering }\end{array}$ & Takashi Kurabuchi \\
\hline $\begin{array}{l}\text { Department of Electrical Engineering, } \\
\text { Faculty of Engineering }\end{array}$ & Mikio Hasegawa \\
\hline $\begin{array}{l}\text { Department of Information and Computer } \\
\text { Technology, } \\
\text { Faculty of Engineering }\end{array}$ & Kozo Fujii \\
\hline $\begin{array}{l}\text { Department of Information and Computer } \\
\text { Technology, } \\
\text { Faculty of Engineering }\end{array}$ & Tomoaki Tatsukawa \\
\hline $\begin{array}{l}\text { Department of Mechanical Engineering, } \\
\text { Faculty of Engineering }\end{array}$ & Hiroshi Gotoda \\
\hline $\begin{array}{l}\text { Department of Physics, } \\
\text { Faculty of Science and Technology }\end{array}$ & Hideyuki Suzuki \\
\hline $\begin{array}{l}\text { Department of Physics, } \\
\text { Faculty of Science and Technology }\end{array}$ & Takayoshi Komura \\
\hline $\begin{array}{l}\text { Department of Applied Biological Science, } \\
\text { Faculty of Science and Technology }\end{array}$ & Kazuya Nakata \\
\hline $\begin{array}{l}\text { Department of Electrical Engineering, } \\
\text { Faculty of Science and Technology }\end{array}$ & Shinichi Kimura \\
\hline $\begin{array}{l}\text { Department of Mechanical Engineering, } \\
\text { Faculty of Science and Technology }\end{array}$ & Ichiro Ueno \\
\hline Photocatalysis International Research Center & Chiaki Terashima \\
\hline
\end{tabular}




\section{Program Details}

\subsection{Lectures}

Twenty six lectures were delivered in the FY2016 T-SEP program. The lecture titles are listed in Table 2. As can be seen, the lectures were on topics related to various science and technology fields, all highly specialized because they were given by researchers and engineers who were experts in their own fields. Simultaneously, the lectures were well prepared and easily understandable by high school students. The series of lectures provided valuable information for every participant, irrespective of their background. A photo of a lecture is shown in Fig. 3. The lectures were recorded to be reviewed later by the participants and further, to be used as educational material.

Table 2. List of lectures for the FY2016 T-SEP program

\begin{tabular}{|c|c|}
\hline Title & Lecturer's name \\
\hline Welcome to space laboratory! & Chiaki Mukai \\
\hline $\begin{array}{l}\text { First scientific experiment in Kibo } \\
- \text { the road to Marangoni } \\
\text { convection }\end{array}$ & $\begin{array}{l}\text { Hiroshi Kawamura } \\
\text { (Tokyo University of Science, } \\
\text { SUWA) }\end{array}$ \\
\hline Life science relationships & Makoto Asashima \\
\hline $\begin{array}{l}\text { Living in space and the global } \\
\text { environment }\end{array}$ & $\begin{array}{l}\text { Mitsuo Oguchi } \\
\text { (WASTEC Inc.) }\end{array}$ \\
\hline $\begin{array}{l}\text { Environmental purification using } \\
\text { photocatalysis technology }\end{array}$ & $\begin{array}{l}\text { Chiaki Terashima } \\
\text { Kazuya Nakata }\end{array}$ \\
\hline $\begin{array}{l}\text { Wonders of surface tension: } \\
\text { fluid physics experiments set in } \\
\text { space }\end{array}$ & Ichiro Ueno \\
\hline $\begin{array}{l}\text { Numerical simulation of air } \\
\text { conditioning in spacecraft }\end{array}$ & Takashi Kurabuchi \\
\hline $\begin{array}{l}\text { Space to watch with X-rays: } \\
\text { neutron stars and black holes }\end{array}$ & Takayoshi Komura \\
\hline $\begin{array}{l}\text { Space to watch with X-rays: high } \\
\text { temperature gas and dark matter }\end{array}$ & Kyoko Matsushita \\
\hline Stars and neutrinos & Hideyuki Suzuki \\
\hline $\begin{array}{l}\text { Space clarified by recent } \\
\text { observation technology }\end{array}$ & Shinji Tsujikawa \\
\hline $\begin{array}{l}\text { Development of solar sail } \\
\text { IKAROS: } \sim \text { first manufacturing in } \\
\text { the world } \sim\end{array}$ & $\begin{array}{l}\text { Eriko Soma } \\
(I S A S / J A X A)\end{array}$ \\
\hline $\begin{array}{l}\text { How to make an on-board device: } \\
\text { what is a device that is working in } \\
\text { the space environment? }\end{array}$ & Shinichi Kimura \\
\hline Learn about rockets & Kozo Fujii \\
\hline $\begin{array}{l}\text { Feel free to space! } \\
\text { About the future of rockets }\end{array}$ & $\begin{array}{l}\text { Takashi Ito } \\
(I S A S / J A X A)\end{array}$ \\
\hline $\begin{array}{l}\text { Wireless communication } \\
\text { technology connections in space }\end{array}$ & Mikio Hasegawa \\
\hline $\begin{array}{l}\text { Science and technology of } \\
\text { combustion in aerospace systems }\end{array}$ & Hiroshi Gotoda \\
\hline $\begin{array}{l}\text { Humans and plants in space: } \\
\text { understanding human partner } \\
\text { "plants" and living together }\end{array}$ & Kazuyuki Kuchitsu \\
\hline $\begin{array}{l}\text { Exploring how plants feel gravity: } \\
\text { the experience of space, parabolic } \\
\text { flight, and ground experiments }\end{array}$ & Masaki Nakano \\
\hline
\end{tabular}

\begin{tabular}{|c|c|}
\hline Title & Lecturer's name \\
\hline Small-scale rocket experiments & $\begin{array}{l}\text { Harunori Nagata } \\
\text { (Research Group of Space } \\
\text { Systems Engineering, } \\
\text { Division of Mechanical and } \\
\text { Space Engineering, } \\
\text { Graduate School of } \\
\text { Engineering, } \\
\text { Hokkaido University) }\end{array}$ \\
\hline My life in space & $\begin{array}{l}\text { Dan Tani } \\
(\text { NASA Astronaut })\end{array}$ \\
\hline $\begin{array}{l}\text { New space utilization developed } \\
\text { by ultra-small satellites and the } \\
\text { future of space engineering } \\
\text { education }\end{array}$ & $\begin{array}{l}\text { Shinichi Nakasuka } \\
\text { (Department of Aeronautics } \\
\text { and Astronautics, } \\
\text { Graduate School of } \\
\text { Engineering, } \\
\text { The University of Tokyo) }\end{array}$ \\
\hline $\begin{array}{l}\text { NASA: exploring space and } \\
\text { understanding Earth }\end{array}$ & $\begin{array}{l}\text { Christopher Blackerby } \\
\text { (NASA Asia Representative) }\end{array}$ \\
\hline Japanese manned space activities & $\begin{array}{l}\text { Takao Doi } \\
\text { (Kyoto University Unit of } \\
\text { Synergetic Studies for Space) }\end{array}$ \\
\hline $\begin{array}{l}\text { How do I design a mission about } \\
\text { what I want to do? } \\
\text { introduction to systems } \\
\text { engineering }\end{array}$ & $\begin{array}{l}\text { Munetaka Ueno } \\
\text { (Center for Planetary Science, } \\
\text { Graduate School of Science, } \\
\text { Kobe University) }\end{array}$ \\
\hline $\begin{array}{l}\text { Development of small satellites: } \\
\text { from Hisaki to SLIM }\end{array}$ & $\begin{array}{l}\text { Shujiro Sawai } \\
\text { (Department of Space Flight } \\
\text { Systems, } \\
\text { ISAS/JAXA) }\end{array}$ \\
\hline
\end{tabular}



Fig. 3. Photo of a lecture.

\subsection{Hands-on trainings}

Six hands-on training sessions were performed in the FY2016 T-SEP program. The list of hands-on training sessions is presented in Table 3; many of the hands-on training sessions were effectively combined with lectures. For example, in the morning when the participants learn the science behind X-ray astronomy, they have the experience of analyzing real data from X-ray observations in the afternoon. A photo of students assembling a space camera is shown in Fig. 4. It is expected that such a combination is quite effective for participants to more deeply understand what they learned in the lecture, based on practical experience. Actual trials performed by their own hands lead to improvements in the technical skills and ideas of the students. Moreover, because the materials of the hands-on training are quite realistic, such as actual experimental data and/or actual devices utilized in space, the participants acquire strong impressions as those felt by real scientists and engineers, and such an impact is expected to strongly affect the student's motivation. 
Table 3. List of hands-on training sessions.

\begin{tabular}{|l|l|}
\hline \multicolumn{1}{|c|}{ Title } & \multicolumn{1}{|c|}{ Teacher } \\
\hline $\begin{array}{l}\text { Numerical simulation of air conditioning } \\
\text { in spacecraft }\end{array}$ & Takashi Kurabuchi \\
\hline $\begin{array}{l}\text { Let's calculate the rotation cycle of } \\
\text { neutron stars }\end{array}$ & Kyoko Matsushita \\
\hline $\begin{array}{l}\text { Space device developments: experience } \\
\text { with assembling space cameras }\end{array}$ & Shinichi Kimura \\
\hline Rocket simulations & $\begin{array}{l}\text { Kozo Fujii } \\
\text { Tomoaki Tatsukawa }\end{array}$ \\
\hline Orbit simulation training & Shinichi Kimura \\
\hline CDF training & Kozo Fujii \\
\hline
\end{tabular}

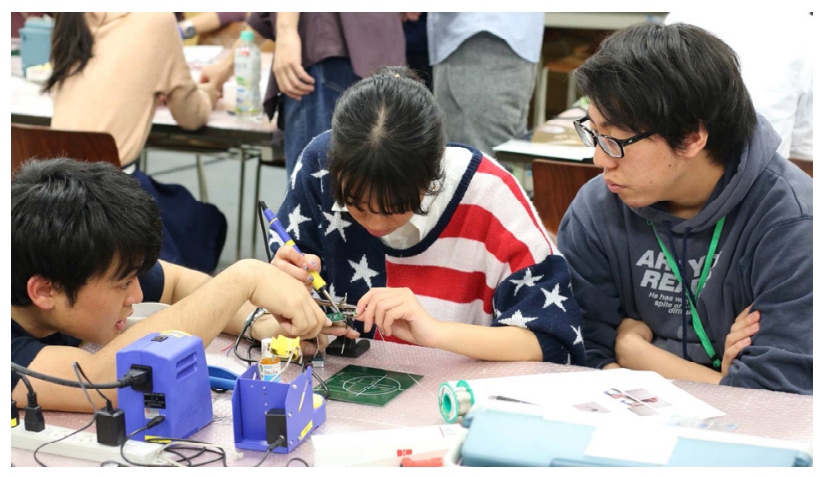

Fig. 4. Photo of students assembling a space camera.

\subsection{Special group experiments}

\subsubsection{Parabolic flight experiment}

Parabolic flight is one of the most familiar experimental methods used to achieve microgravity conditions. When an airplane flies a vertical parabolic trajectory, microgravity can be achieved inside the airplane for about $20 \mathrm{~s}$. Diamond Air Service offer parabolic flight services for conduction of experiments and/or provision of experience of microgravity conditions. We chartered their flights on two consecutive days.

The participants of T-SEP were divided into six teams to perform parabolic flight experiments. Due to scheduling constraints, high school participants were separated from university participants; therefore, we had three university teams and three high school teams.

The experiments performed in parabolic flight need to clear various constraints. For example, the experimental equipment needs to be smaller than the size and weight limitations. Time is another important constraint when performing experiments. The periods of microgravity during a parabolic flight are limited to $20 \mathrm{~s}$; therefore, each experiment should give results in a short period. The material that can be utilized for experiments is also limited. Liquid is limited in volume, and needs to be kept inside the equipment without any leakage.

Each team is expected to consider these constraints and propose experiments that can be performed subjected to such limitations. Based on their proposal, they then need to organize the experiment apparatus themselves. In order to prepare the experiment and perform the in-flight experiments, team management and schedule management are especially important. Moreover, the date of the chartered flights is strictly determined beforehand, therefore they cannot perform any experiment if the preparation of experiments is not finished on the specified day, no matter how important the experiment is.

These issues are especially important when performing space missions; therefore, the group experiment on parabolic flight is a good simulation of a space mission and quite effective in teaching the basic processes involved in one.

The themes of the parabolic flight experiments in the FY2016 are listed in Table 4. As shown in Table 4, various experiments were performed utilizing the microgravity environment. A photo of parabolic flight experiment is shown in Fig. 5. As a result, there were a few teams that got good results, whereas a few teams which did not obtain satisfactory results. Regardless, the participants had a fulfilling experience, both along the preparation process and during the experiment itself. The results and movie presentations of the parabolic flight experiment were also utilized as space educational materials and are presented on the T-SEP website.

Table 4. Themes of parabolic flight experiments

\begin{tabular}{|c|c|}
\hline Team name & Theme \\
\hline $\begin{array}{l}\text { Raspberry-fly } \\
\text { (University } \\
\text { student team) }\end{array}$ & $\begin{array}{l}\text { Demonstration experiment on control of multi- } \\
\text { rotor vehicle under microgravity condition }\end{array}$ \\
\hline $\begin{array}{l}\text { Team SUBARU } \\
\text { (University } \\
\text { student team) }\end{array}$ & $\begin{array}{l}\text { - Spreading structure experiment } \\
\text { - Capillary tube experiment }\end{array}$ \\
\hline $\begin{array}{l}\text { Swing By Me } \\
\text { (University } \\
\text { student team) }\end{array}$ & $\begin{array}{l}\text { Simulation experiment of swing-by navigation } \\
\text { and educational materials development }\end{array}$ \\
\hline $\begin{array}{l}\text { Chiki×2BOOM } \\
\text { (High school } \\
\text { student team) }\end{array}$ & $\begin{array}{l}\text { - Development of a pipette for the International } \\
\text { Space Station } \\
\text { - Behavioral motion of raw egg under zero } \\
\text { gravity: experiment to mix albumen and yolk } \\
\text { of an egg by self-made mixer }\end{array}$ \\
\hline $\begin{array}{l}\text { Team KEN } \\
\text { (High school } \\
\text { student team) }\end{array}$ & $\begin{array}{l}\text { Space elevator climber ascent and descent } \\
\text { experiment }\end{array}$ \\
\hline $\begin{array}{l}\text { SUBARU } \\
\text { (High school } \\
\text { student team) }\end{array}$ & $\begin{array}{l}\text { - Experiment regarding reduction of } \\
\text { electromagnetic induction and G-jitter } \\
\text { - Gravity change and escape behavior analysis } \\
\text { from particle cluster: investigation on getting } \\
\text { off a crowded train under the influence of } \\
\text { intrinsic stress }\end{array}$ \\
\hline
\end{tabular}



Fig. 5. Photo of parabolic flight experiment. 


\subsubsection{CANSAT training}

CANSAT is a small size simulated satellite. ${ }^{1)}$ In many cases, it is launched by amateur rocket or balloon and conducts various experiments during descent and/or once on the ground running like a rover. The development process for CANSAT is a good opportunity to learn spacecraft development processes because it includes various aspects of spacecraft development, such as mission design and hardware development and verification. ${ }^{1)}$ Similar to parabolic flight experiments, T-SEP considers that CANSAT can provide effective materials and is included as another special group experiment.

In addition to parabolic flight experiments, CANSAT requires knowledge and skill in various technological areas, especially electronics, software, and communications. Another important issue with CANSAT is autonomous control. Because CANSAT is expected to be self-controlled once it is launched, the CANSAT developer needs to consider adaptation strategies under nominal and off-nominal situations. These processes are essential to developing satellite and/or explorer vehicles.

In the CANSAT program, 30 students were divided into 5 groups. Each group had both university members and high school members; therefore, the teams were expected to cooperate across different ages and levels of experience.

In the FY2016 CANSAT program, participants were asked to propose a technical demonstration mission for future Mars exploration; the proposed missions are shown in Table 5. Because the schedule was extremely tight, many teams struggled to achieve everything that they had originally expected to do, but the challenging experience of designing a highly complicated system was worthwhile for all participants. A photo of a CANSAT experiment is shown in Fig. 6.

Table 5. Mission contents of CANSAT training.

\begin{tabular}{|l|l|}
\hline \multicolumn{1}{|c|}{ Group name } & \multicolumn{1}{|c|}{ Theme } \\
\hline Hashiritai & Aircraft control in landing on Mars \\
\hline Shooting star & Astronomical observation from Mars \\
\hline Iroha & Fixed point observation on Mars \\
\hline terra-forming & Consideration of another method of movement \\
\hline PyonSat & $\begin{array}{l}\text { Independent mobility experiment using a } \\
\text { jumping mechanism }\end{array}$ \\
\hline
\end{tabular}

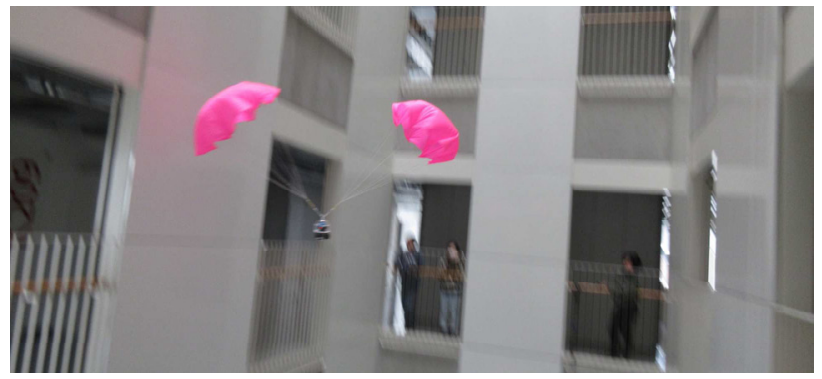

Fig. 6. Photo of a CANSAT experiment

\subsubsection{Space-related facilities tours}

T-SEP includes a facility tour program to visit spacerelated facilities such as laboratories and companies to see cutting-edge research and developments relating to space activities.

As a space-related facilities tour in the FY2016, T-SEP participants visited the NEC Fuchu Office and the National Astronomical Observatory of Japan (NAOJ) Mitaka Campus. In the NEC Fuchu Office, after the NEC staff explained the outline of their space related project, participants visited the manufacturing site, inspection sites, and environmental tests facilities for the satellite equipment. In the NAOJ, the participants had an opportunity to see areas that are not open for public, such as the interior of the Solar Tower Telescope (Einstein Tower). A photo from the NAOJ visit is shown in Fig. 7. Students were able to acquire knowledge and form a lasting impression of space development activities by visiting places that lead space development in Japan.

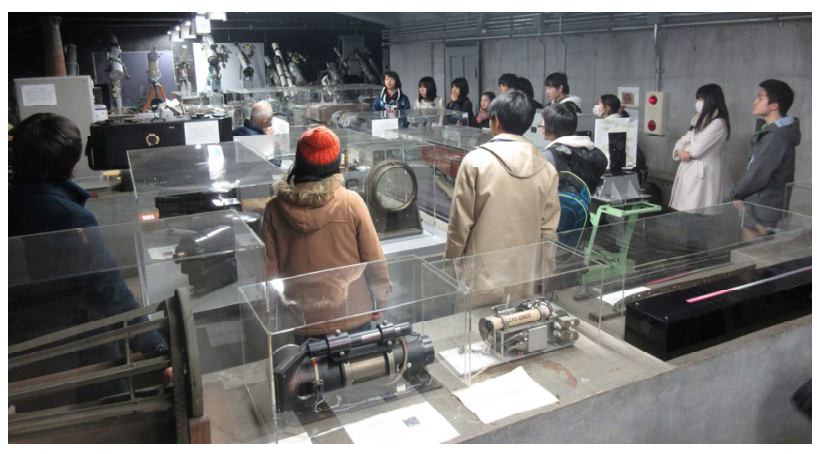

Fig. 7. Photo from the NAOJ visit.

\subsubsection{International visit and exchange program}

To effectively promote space missions, international cooperation is essential. To enhance international cooperation, young space engineers and researchers should acquire both communication capabilities such as mastering foreign languages and experience foreign activities and ways of thinking directly. Based on this idea, T-SEP includes an international visiting program. In the program, the participants fly to a foreign country for one week and visit space agencies, universities, and companies.

In the FY2016 international visit program, participants visited Houston and the Silicon Valley in the USA for one week. The visit schedule is shown in Table 6. Even though the period was short, the schedule was highly condensed and included many interesting visits.

At the NASA Johnson Space Center, the participants learned the history of space development in the USA and the current development situation. A photo from the NASA Johnson Space Center tour is shown in Fig. 8. At the JAXA Houston Office, they listened to a lecture on the role of the office in Houston. At the Ames Research Center, they visited the NASA Advanced Supercomputing Facility and the Vertical Motion Simulator. In Silicon Valley, they visited every place there with the guidance of NorCal TUS Alumni Association, Kumagai, K. Visits to the sites leading the world's space development efforts made a strong impression on the participants and inspired them to develop an international perspective. 
Table 6. Schedule of international visit.

\begin{tabular}{|c|l|}
\hline Date & \multicolumn{1}{|c|}{ Visited place } \\
\hline 1 & Japan $\rightarrow$ Houston \\
\hline 2 & NASA Johnson Space Center, JAXA Houston Office \\
\hline 3 & Rice University \\
\hline 4 & Houston $\rightarrow$ Silicon Valley \\
\hline 5 & Ames Research Center, Intel Museum \\
\hline 6 & Stanford University, Silicon Valley \\
\hline 7 & Silicon Valley $\rightarrow$ Japan \\
\hline
\end{tabular}

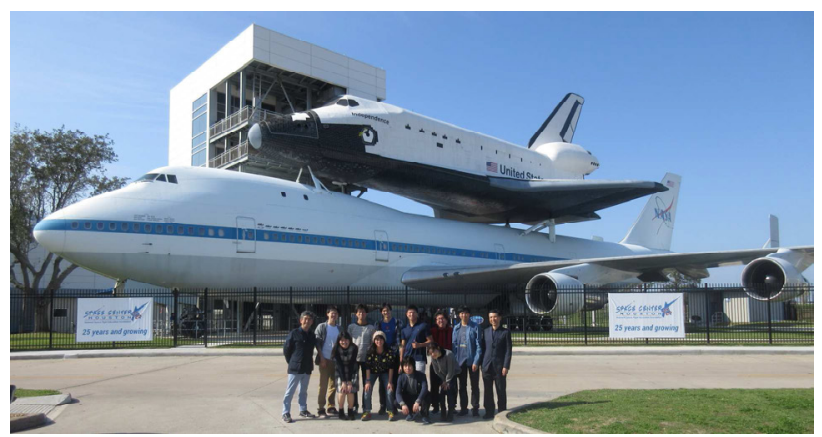

Fig. 8. Photo from the NASA Johnson Space Center tour.

\section{Lessons Learned from Two Years' Execution of T- SEP}

\subsection{Objective of T-SEP and analysis of questionnaires from the participants}

In the T-SEP program, we expected the participants to acquire the following knowledge and skills, not only from lectures but also from various active-learning activities such as parabolic flight, CANSAT, and international site visit.

1) Realistic knowledge and skills on space technologies and science

2) Promotion and presentation skills to enroll new space missions

3) Internationality to realize international cooperation

4) Communication and team management skills

5) Project formation, designing, and management skills

We believe that these skills are essentially important to propose and to proceed with space missions.

To confirm the effectiveness of T-SEP, we asked the participants to answer questionnaires. Figure 9 shows the average of the improvement level on the skills mentioned above, rated as 0 for the worst and 5 for the best. As shown in the table, every skill indicates a very high improvement level of more than 4 , although it is self-assessment by the participant. The improvement level of "1) Realistic knowledge and skills on space technologies and science" shows the relatively highest level; therefore, we can confirm the effectiveness of various lectures by the highly specialized members such as astronauts, researchers, and engineers. Active learning group programs, such as parabolic flight and CANSAT, are also effective to improve project management skills and quite impressive for the participants, because "4) Communication and team management skills" and "5) Project formation, designing, and management skills" also show a very high level. On the other hand, because "3) Internationality to realize international cooperation" shows a relatively low score, we recognize this issue as a problem to be improved in T-SEP.

In addition to the results of questionnaires, the following aspects suggest the effectiveness of T-SEP.

1) Participants in T-SEP made three presentations on their experience in T-SEP in international conferences. One of the presentations was awarded the best-presentation award in the conference.

2) Several of the first participants made a group to develop their own CANSAT and participated in the CANSAT competition.

3) Many members decided to enter post-graduate courses and are seeking the carrier path to the space bencher companies.

Considering these results, it can be said that T-SEP is quite effective as an entry-level educational program for space technologies and science.

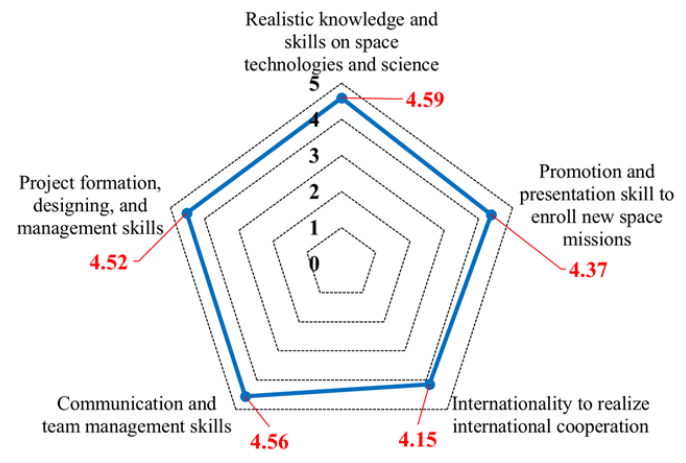

Fig. 9. The average of the improvement level on the skills assessed by questionnaires.

\subsection{As a participant of T-SEP}

As mentioned previously, the author applied to T-SEP and participated as one of the first students. The author applied to take a course in the space development field; recruitment for T-SEP began during third-year undergraduate course selection. Through lectures, hands-on training, and special group experiments, the author acquired cutting-edge and practical knowledge and experience regarding space science and space development technology, as intended. For example, in the lecture "Welcome to space laboratory!" presented by Mukai, the author learned more about the actual space experiments and experiences by real astronauts and the habits of plants and animals under zero gravity. In assembling space cameras and rocket simulations, the author experienced them while considering the optimum design for achieving the space missions and was able to acquire knowledge and techniques for the design suitable for the work process and purpose. The parabolic-flight experiment was particularly memorable. To plan the experiment from scratch, the author created a work breakdown structure (WBS). Based on the WBS, the author made a schedule by creating a Gantt chart. The author assumed real and unexpected (off nominal) situations and prepared an experiment procedure manual in seconds that can correspond to both. The author boarded an aircraft as a flight 
crew member and experienced the gyroscopic effect with his body. A photo of the parabolic flight experiment by the author is shown in Fig. 10. During the experiment, an unexpected situation occurred where the body posture could not be controlled well at first. However, countermeasures were devised for a flexible response, and the experiment was successfully performed. With this experience, the author realized that careful preparation is the most important part of every project and acquired valuable experience that is only available with T-SEP. Moreover, it was important that the author first met with a variety of specialized teachers, researchers, engineers, and students and built friendly relations. Throughout the program, the author acquired a wider range of knowledge and techniques, management skills, and communication skills. In addition, the author was exposed to various concepts related to space development, which increased the desire for further learning about space development. Because of these experiences, the author is currently pursuing a master's thesis related to the aerospace materials at JAXA as a part of the Department of Mechanical Engineering, Graduate School of Science and Technology, TUS. The experience with T-SEP is being incorporated into this research.

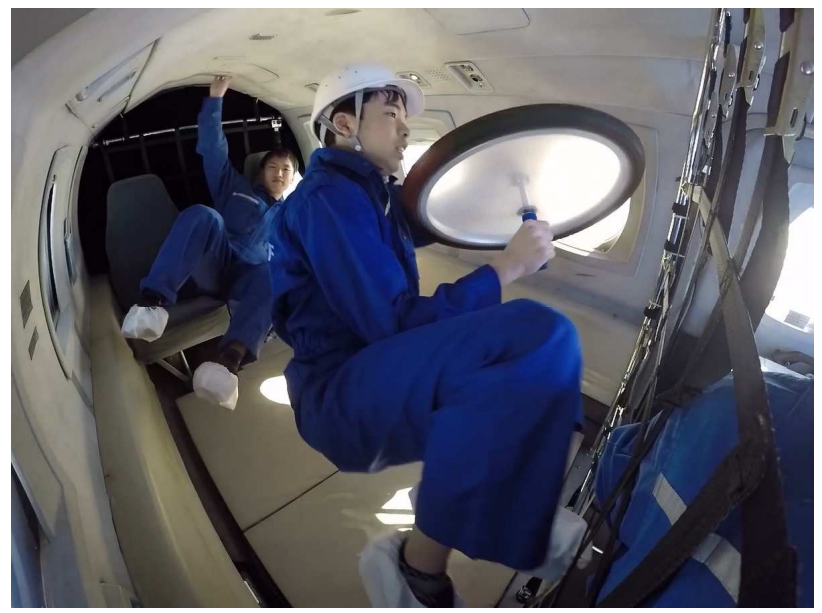

Fig. 10. Photo of the parabolic flight experiment by the author.

\subsection{Re-education system as a mentor}

A unique and effective feature of this program is to allow the participants of previous T-SEP programs to participate as supporting instructors, also known as the "mentors." In the FY2016 T-SEP program, 12 mentors supported the program not only as assistants for the lectures and hands-on training, but also as the instructors of the active-learning group work, thus effectively utilizing their own experiences. Such an experience is vital for the mentored students to improve their technological skills as well as their education and team management skills. Because we expect the participants to become leading educators, engineers, and researchers, these experiences will be effective when they are able to teach their own students or when they lead and coordinate teams in the future.

\subsection{As a mentor of T-SEP}

As noted above, the author is a mentor and took advantage of the experience of being one of the first students. Because a mentor is in a position of providing support and encouragement, it is important to think about the education of the students first. For example, if a mentor simply tells the answer to a student, the student's own problem-solving ability does not improve. If the mentor's own ideas are adopted as the subject of a team's proposed project, it will not lead to student growth. A photo of discussion about CANSAT with students is shown in Fig. 11. As a mentor, the author provided simple points and tried to make the students actively solve the problem. Even so, education-aware support was difficult, and there were many incidents where the author was concerned about the amount of information he revealed to the students, as they noted. However, this allowed the author to experience teaching and understand the significance of education. By acting in a supportive position, the author was able to acquire flexible thinking and action to achieve remarkable results.

In the special group experiments, mentors are positioned in each group. Participants who are beginners of the program receive guidance from the mentor, which becomes a hint to solve the problem with their own skills. Mentors who are experienced in the program can provide a good opportunity to teach their own knowledge acquired in the program and to demonstrate their skills. In addition, mentors have developed the skills to teach the beginners appropriately. One of the participants said that "I am grateful to mentors for the fact that we have troubled together to advance this program and made things together. I think that it is a very effective mechanism that seniors give advice on their own experience as a mentor and guidelines when participants are troubled." Not only that, it is a good opportunity to improve communication skills by maintaining a moderate sense of distance between participants and mentors. Therefore, through the intervention of mentors, there are educational effects to promote the growth of participants and mentors. Because the mentoring system has many educational advantages for both the supporter and the supported, it should be actively adopted in education and projects.

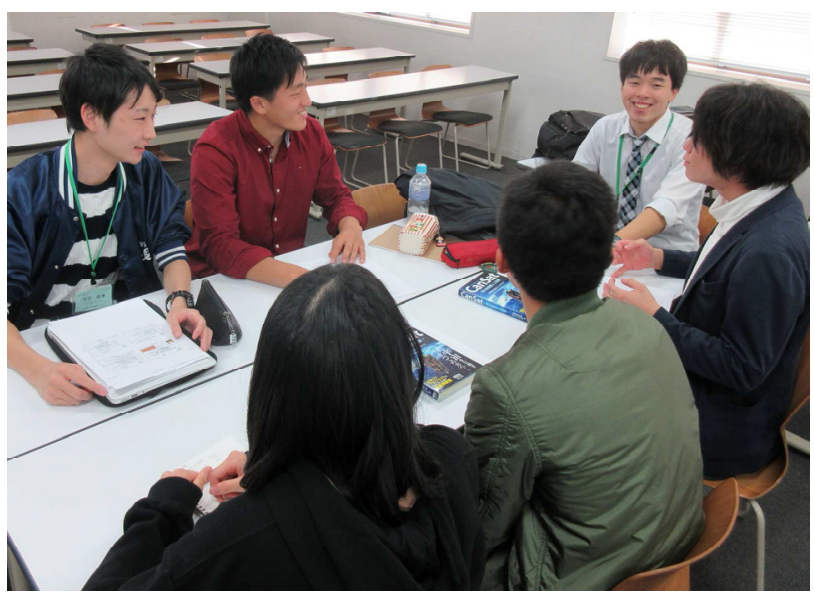

Fig. 11. Photo of discussion about CANSAT with students. 


\section{Conclusion}

This paper introduces T-SEP from the viewpoint of a mentor having experience as one of the first students. Implementation of T-SEP is expected to lead to the growth of the next generation of science and mathematics educators, and students can become space scientists and engineers and contribute to building the foundation of space education in the future.

\section{Acknowledgments}

We would like to express special thanks to the cooperation of JAXA, Nagoya University, Diamond Air Service Inc.,
Japan Space Forum, NEC Corporation, NAOJ, NASA, NorCal TUS Alumni Association, and Kumagai, K.

This program is implemented by the Aerospace Science and Technology Promotion Program (Development of "Space Educational Program" learned with cutting-edge space technology) of Ministry of Education, Culture, Sports, Science and Technology (MEXT).

\section{References}

1) University Space Engineering Consortium (UNISEC): CanSatUltra-small simulated satellite-, Ohmsha, Tokyo, 2014, p. 2 (in Japanese). 